\title{
Multidisciplinary optimization of an NLF forward swept wing in combination with aeroelastic tailoring using CFRP
}

\section{DLR contribution to the LuFo IV joint research project AeroStruct}

\author{
Tobias Wunderlich · Sascha Dähne · Lars Heinrich · Lars Reimer
}

\begin{abstract}
This article introduces a process chain for commercial aircraft wing multidisciplinary optimization (MDO) based on high fidelity simulation methods. The architecture of this process chain enables two of the most promising future technologies in commercial aircraft design in the context of MDO. These technologies are natural laminar flow (NLF) and aeroelastic tailoring using carbon fiber reinforced plastics (CFRP). With this new approach the application of MDO to an NLF forward swept composite wing will be possible.

The main feature of the process chain is the hierarchical decomposition of the optimization problem into two levels. On the highest level the wing planform including twist and airfoil thickness distributions as well as the orthotropy direction of the composite structure will be optimized. The lower optimization level includes the wing box sizing for essential load cases considering the static aeroelastic deformations. Additionally, the airfoil shapes are transferred from a given NLF wing design and the natural laminar flow is considered by prescribing laminar-turbulent transition locations.
\end{abstract}

\section{T. Wunderlich}

German Aerospace Center,

Institute of Aerodynamics and Flow Technology,

Lilienthalplatz 7, 38108 Braunschweig, Germany

E-mail: tobias.wunderlich@dlr.de

S. Dähne

German Aerospace Center,

Institute of Composite Structures and Adaptive Systems,

Lilienthalplatz 7, 38108 Braunschweig, Germany

E-mail: sascha.daehne@dlr.de

\section{Heinrich}

German Aerospace Center,

Institute of Composite Structures and Adaptive Systems,

Lilienthalplatz 7, 38108 Braunschweig, Germany

E-mail: lars.heinrich@dlr.de

\section{Reimer}

German Aerospace Center,

Institute of Aerodynamics and Flow Technology,

Lilienthalplatz 7, 38108 Braunschweig, Germany

E-mail: lars.reimer@dlr.de
Optimization results of the multidisciplinary process chain are presented for a forward swept wing aircraft configuration on conceptual design level. The results show a fuel burn reduction in the order of $9 \%$ for the design mission.

Keywords multidisciplinary optimization (MDO) · wing optimization · natural laminar flow (NLF) - transonic aerodynamics $\cdot$ aeroelastic tailoring $\cdot$ carbon fiber reinforced plastics (CFRP) · static aeroelasticity · fluid-structure coupling · Reynolds-averaged Navier-Stokes (RANS) . finite element method (FEM)

\section{List of symbols}

$\begin{array}{ll}A & \text { Aspect ratio } \\ b & \text { Span } \\ \text { c } & \text { Vector of constraints } \\ C_{L} & \text { Lift coefficient } \\ C_{l} & \text { Local lift coefficient } \\ C_{D} & \text { Drag coefficient } \\ C_{D, \text { res }} & \text { Residual drag coefficient } \\ c & \text { Chord length } \\ F C & \text { Fuel consumption }\left(F C=\frac{m_{F}}{R m_{P}}\right) \\ g & \text { Acceleration of gravity } \\ H & \text { Altitude } \\ L / D & \text { Lift-to-drag ratio } \\ M a & \text { Cruise Mach number } \\ m_{F} & \text { Fuel mass } \\ m_{F, r e s} & \text { Reserve fuel mass } \\ m_{i} & \text { Aircraft mass at flight mission segment } i \\ m_{M T O} & \text { Maximum take-off mass } \\ m_{R e s} & \text { Residual mass (structural mass without the wing) } \\ m_{P} & \text { Payload } \\ m_{W} & \text { Wing mass } \\ m_{W, b o x} & \text { Wing box mass } \\ n & \text { Load factor }(n=L / W) \\ n_{c p l} & \text { Number of fluid-structure coupling iteration } \\ R & \text { Range }\end{array}$




$\begin{array}{ll}S & \text { Wing area } \\ T S F C & \text { Thrust specific fuel consumption } \\ t, t / c & \text { Absolute and relative airfoil thickness } \\ V & \text { Flight speed } \\ x, y, z & \text { Coordinates } \\ x_{T} & \text { Location of laminar-turbulent transition } \\ \mathbf{x} & \text { Vector of design parameters } \\ \mathbf{y} & \text { Vector of response variables }\end{array}$

\section{Greek symbols}

$\begin{array}{ll}\Delta & \text { Difference } \\ \varepsilon & \text { Wing twist angle (jig-shape) } \\ \gamma & \text { Dimensionless local lift }\left(\gamma=\frac{C_{l} c}{2 b}\right) \\ \eta & \text { Dimensionless span coordinate }\left(\eta=\frac{2 y}{b}\right) \\ \lambda & \text { Taper ratio } \\ \varphi_{L E} & \text { Leading edge sweep angle } \\ \varphi_{O D} & \text { Orthotropy angle of the composite material }\end{array}$

\begin{tabular}{|c|c|}
\hline \multicolumn{2}{|c|}{ Abbreviations } \\
\hline ASCII & $\begin{array}{l}\text { American } \underline{\text { Standard Code for }} \\
\text { Information Interchange }\end{array}$ \\
\hline CAD & Computer-Aided Design \\
\hline CFD & Computational Fluid Dynamics \\
\hline CFRP & 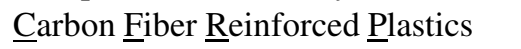 \\
\hline CPACS & 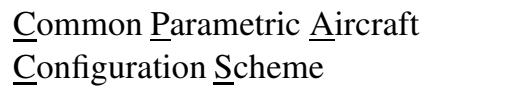 \\
\hline CS & Certification $\underline{\text { Specifications }}$ \\
\hline CSM & 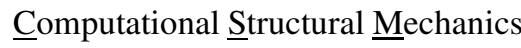 \\
\hline DLR & German Aerospace Center \\
\hline FAR & 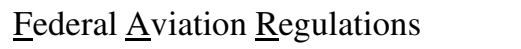 \\
\hline FE & Finite Element \\
\hline HPC & High $\underline{\text { Performance } \text { Computing }}$ \\
\hline LC & Load Case \\
\hline MDO & 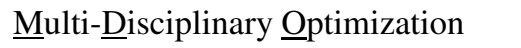 \\
\hline MoS & $\underline{\text { Margins of } \underline{\text { Safety }}}$ \\
\hline NLF & Natural Laminar Flow \\
\hline
\end{tabular}

\section{Introduction}

The environmental impact of aviation increases with the rapid growth of air travel and transport. For this reason efficiency of future air transport must be improved significantly. The research and development of future transport aircraft have to meet this challenge. A Strategic Research Agenda has been developed by the Advisory Council for Aeronautics Research in Europe (ACARE). The goals of the European aeronautical research have been formulated in this research agenda and have been published in the "Vision 2020" [1], [2] and the "Flightpath 2050" [3]. In order to protect the environment and to preserve the energy supply a $50 \%$ reduction of the $\mathrm{CO}_{2}$ emissions per passenger kilometer has been requested for the year 2020 based on the values of the year 2000. The airframe contribution should be in the order of $20 \%$ to $25 \%$ in terms of fuel consumption reduction.

To achieve these challenging goals the development timescales for new technologies including new aircraft concepts have to be reduced significantly. For the assessment of an aircraft configuration it is essential to consider all relevant disciplines and their interactions on overall aircraft level. The consideration of new technologies and aircraft concepts requires a physics based approach because no statistics are available anymore. In order to represent the physics in a realistic manner, accurate simulation tools have to be applied. With increasing accuracy of the disciplinary simulations the geometrical description has to be improved, too. This inherently leads to increased computational costs. The development of accurate and fast numerical simulation and optimization processes is getting more and more important. In this context new capabilities in the areas of process architecture, program interfaces, parallelization and the usage of high performance computing (HPC) are required.

The combination of increasing computer resources and advanced numerical simulation tools enables the accurate prediction of flight performance of a transport aircraft configuration [4]. The use of these high fidelity simulation programs for aerodynamic design and optimization has been demonstrated in the MEGADESIGN project (Kroll et al. [5], [6], [7], [8] and Gauger [9]).

State of the art high fidelity analysis methods already routinely include fluid-structure coupling of the aircraft wing for a given structural model. The consideration of fluidstructure interactions gets more important for the accurate performance and load prediction of highly flexible wings.

Improvements in automation and coupling of accurate simulation methods in combination with advances in numerical optimization strategies lead to the emergence of MDO based on high fidelity methods.

Multidisciplinary wing optimizations for realistic aircraft configurations under consideration of static aeroelasticity have been shown for example by Piperni et al. [10] for a large business jet and by Chiba et al. [11] for a regional jet.

The challenge in using MDO based on highly accurate methods is the large number of design parameters and the increased computing effort. To overcome this issue, the adjoint method enables the efficient calculation of the flow variable gradients as a function of the design parameters for gradient based optimizations. The adjoint method was used by Jameson, Leoviriyakit and Shankaran [12] for a gradient based multidisciplinary wing optimization with fluidstructure coupling. Up-to-date applications of the adjoint approach for multidisciplinary wing optimization have been 
shown in the publications of Kenway and Martins [13], Kenway, Kennedy and Martins [14] and Liem, Kenway and Martins [15]. These publications show that the gradient based optimization using the adjoint approach is an adequate method for multidisciplinary wing optimization with high fidelity simulation programs and a large number of design parameters.

In this article an alternative MDO approach is introduced for cases in which gradients cannot be computed efficiently for all relevant disciplines. This applies particularly to cases which involve laminar-turbulent transition prediction and structural sizing of composite structures using proprietary codes. Furthermore, a certain degree of flexibility in the process architecture and optimization strategy is desired. Especially the option to use optimization strategies seeking for the global optimum is important. The implementation of the introduced process chain brings all together in terms of aerodynamic simulation solving the Reynoldsaveraged Navier-Stokes equations (RANS) with consideration of laminar flow, using the finite element method (FEM) for structural analysis and sizing of composites structures including aeroelastic tailoring and fluid-structure coupling in an efficient gradient free engineering approach. With the successful integration of the commercial software CATIA ${ }^{\circledR}$ V5, Pointwise $^{\circledR}$, MSC Nastran ${ }^{\mathrm{TM}}$ and HyperSizer ${ }^{\circledR}$ in combination with the DLR TAU-code under FlowSimulator environment in a process chain the relevance for industrial applications is shown. The efficiency of the process chain has been reached with the parallelization of the aerodynamic simulation, the parallel computation of all flight and load cases and the integration of the structural sizing in the fluid-structure coupling iteration loop. An further advantage of the introduced process chain is the integrated surrogate based optimization (SBO) method, which is an adequate strategy to find the global optimum.

The application of MDO to new aircraft concepts and technologies using high fidelity methods is very promising. By using MDO an accurate comparison between optimal solutions based on conventional and new technologies will be possible. This facilitates an adequate assessment of new concepts and technologies on the one hand. On the other hand, this requires the availability of physics-based simulation models and efficient programs with adequate interfaces.

To improve the aerodynamic efficiency of commercial aircraft, modern technologies for drag reduction have to be applied. A short overview of aerodynamic wing design and corresponding technologies is given for example by Horstmann and Streit [16]. One of the most promising drag reduction technologies is laminar flow control (LFC). The potential of this technology for drag reduction of commercial aircraft has been described by Schrauf [17] and Green [18] for example.
In 1979, Boeing already investigated the benefit of NLF on large transport aircraft [19]. This study shows that the aircraft having an NLF wing design was not competitive against a turbulent wing design taking the top level aircraft requirements as a basis for comparison. In the DLR project LamAiR [20], however, the concept of forward sweep for laminar wings as proposed by Redeker and Wichmann [21] shows significant potential for efficiency improvements. In this project a multidisciplinary wing design of a forward swept wing having NLF and a composite structure including aeroelastic tailoring has been performed. The results have been published by Kruse et al. [22].

The work on aeroelastic tailoring is summarized by Shirk et al. [23]. In this publication aeroelastic tailoring is described as "...embodiment of directional stiffness into an aircraft structural design to control aeroelastic deformation, static or dynamic, in such a fashion as to affect the aerodynamic and structural performance of that aircraft in a beneficial way.". Additionally, the advantages of composite materials on forward swept wings are explained. Tailoring the primary stiffness direction relative to the structural reference axis introduces a bend-twist-coupling that can be used to counteract the susceptibility of forward swept wings to static divergence. Dähne et al. [24] investigated the influence of aeroelastically tailored composites on structural mass. In this study an automated structural sizing process has been applied with the simplification that the aerodynamic loads remained fixed.

In striving for the capability to assess new wing technologies by development and application of an MDO process chain has been one of the main topics in DLR's contribution to the LuFo IV joint research project AeroStruct. In the scope of the project a process chain for multidisciplinary wing optimization considering new wing technologies such as forward sweep, NLF, composite materials and aeroelastic tailoring have been developed. In the setup of the process chain it was made sure that the aerodynamic loads of all load cases entering the structural sizing always result from fluidstructure coupled simulations. Wunderlich [25] showed that this has crucial influence on the multidisciplinary wing optimization results.

\section{Process chain for multidisciplinary wing optimization}

A process chain for multidisciplinary wing optimization based on high fidelity simulation methods has been developed. The developed process chain can be characterized by the following items:

- Usage of a central parametric file format,

- Automated grid generation for aerodynamic simulation,

- Automated structural model generation for structural simulation, 


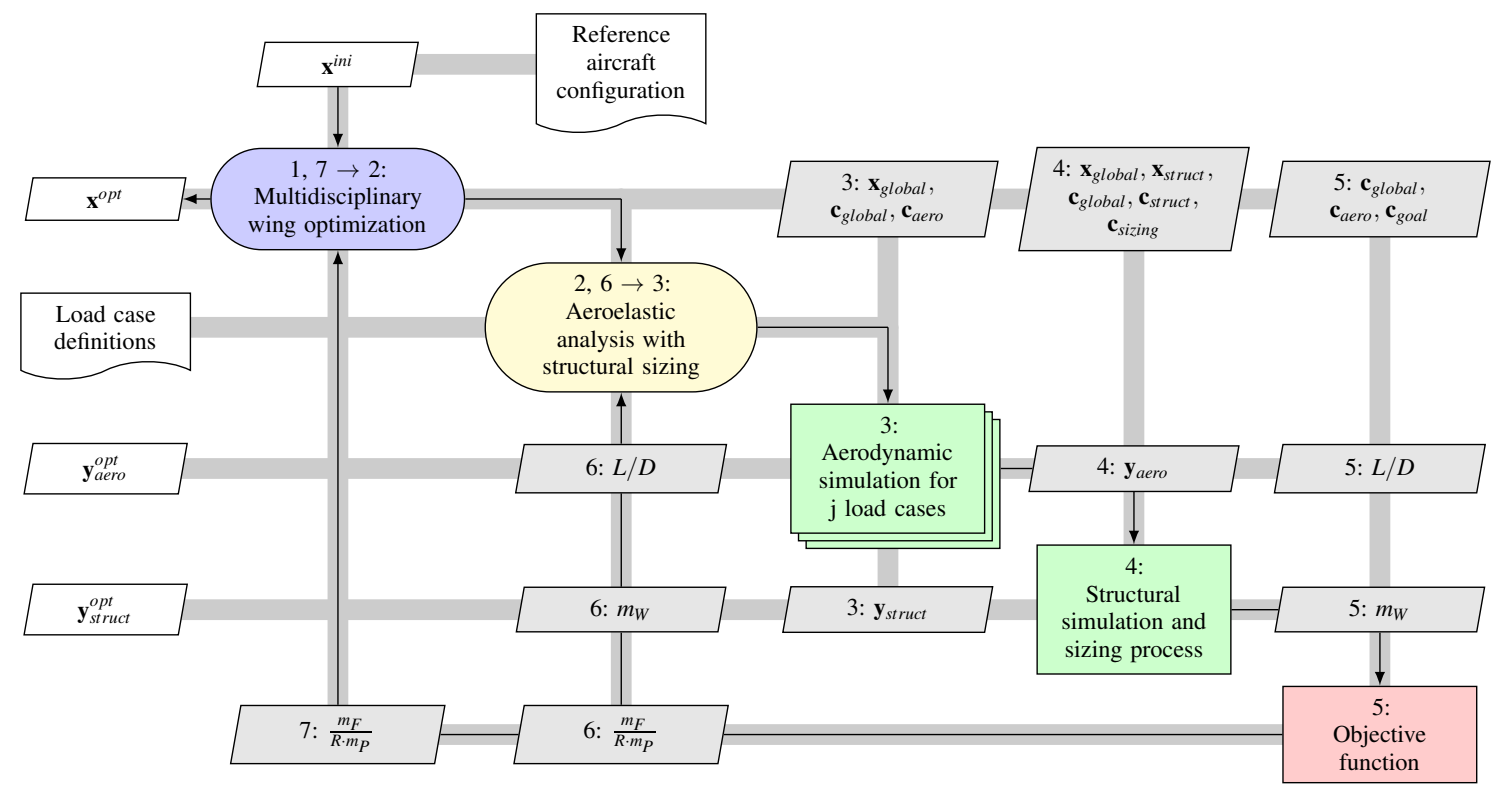

Fig. 1 Flow chart of the process chain for multidisciplinary wing optimization.

- Parallel and efficient aeroelastic analysis for j load cases,

- Structural wing box sizing for composite structures,

- Consideration of NLF by prescribing laminar-turbulent transition locations,

- Applicability for large geometrical changes and global optimization strategy.

The selected MDO architecture falls in the category of MDF-optimizations (Multi-Disciplinary Feasible) and can be described as ASO (Asymmetric Subspace Optimization) according to Martins and Lambe [26]. In the MDF architecture a full multidisciplinary analysis (MDA) is performed for each optimization iteration. This means that the investigated design fulfills all constraints in each optimization step and hence is called a feasible design.

In Fig. 1 the process chain is illustrated with an XDSMdiagram (Extended Design Structure Matrix) [27]. This type of diagram combines the information of process flow between computational components with the information of data dependency. Each component in the diagram takes input data from the vertical direction and provides output data from the horizontal direction. Input and output data are marked by parallelograms. Thick gray lines show the data flow. Thin black arrows indicate the process flow, and a numbering system is used to define the order in which the components are executed.

The starting point for a multidisciplinary wing optimization is a fully parametric description of the aircraft using the Common Parametric Aircraft Configuration Schema (CPACS). This initial CPACS dataset has to be generated manually or with a program in an automated way for a given reference aircraft configuration. To support the process of transferring the outer geometry of given nonparametric models an in-house program exists. Furthermore, the initial vector of design parameters $\mathbf{x}^{i n i}$ is determined by the reference aircraft configuration. The load case definitions for the structural sizing have to be identified and stored in the CPACS dataset.

All disciplinary simulation programs in the process chain provide interfaces to this central hierarchical ASCII text file format. In section 2.2 the parametric model and the CPACS dataset are described in more detail.

The driver component controls the optimization iteration and is represented in Fig. 1 by a blue rounded rectangle. Based upon a design parameter variation and a following transfer to the CPACS dataset the disciplinary models are built or updated automatically. Thereby, the vector of design parameters $\mathbf{x}$ describes the wing planform including twist and airfoil thickness distributions and the orthotropy direction of the composite structure.

The static aeroelastic analysis is then run in parallel for all load cases including the design point under cruise flight conditions. In the actual implementation, the process chain is limited to steady state maneuver load cases and only the wing-fuselage configuration is analysed within the high fidelity simulation process.

For each load case the surface pressure distribution and aerodynamic coefficients of the wing are determined by solving the Reynolds-averaged Navier-Stokes equations (RANS) within a numerical flow simulation. Elastic characteristics of the wing and its internal loads are determined using the finite element method (FEM). Subsequently, the wing mass is deduced by processing these internal loads. 


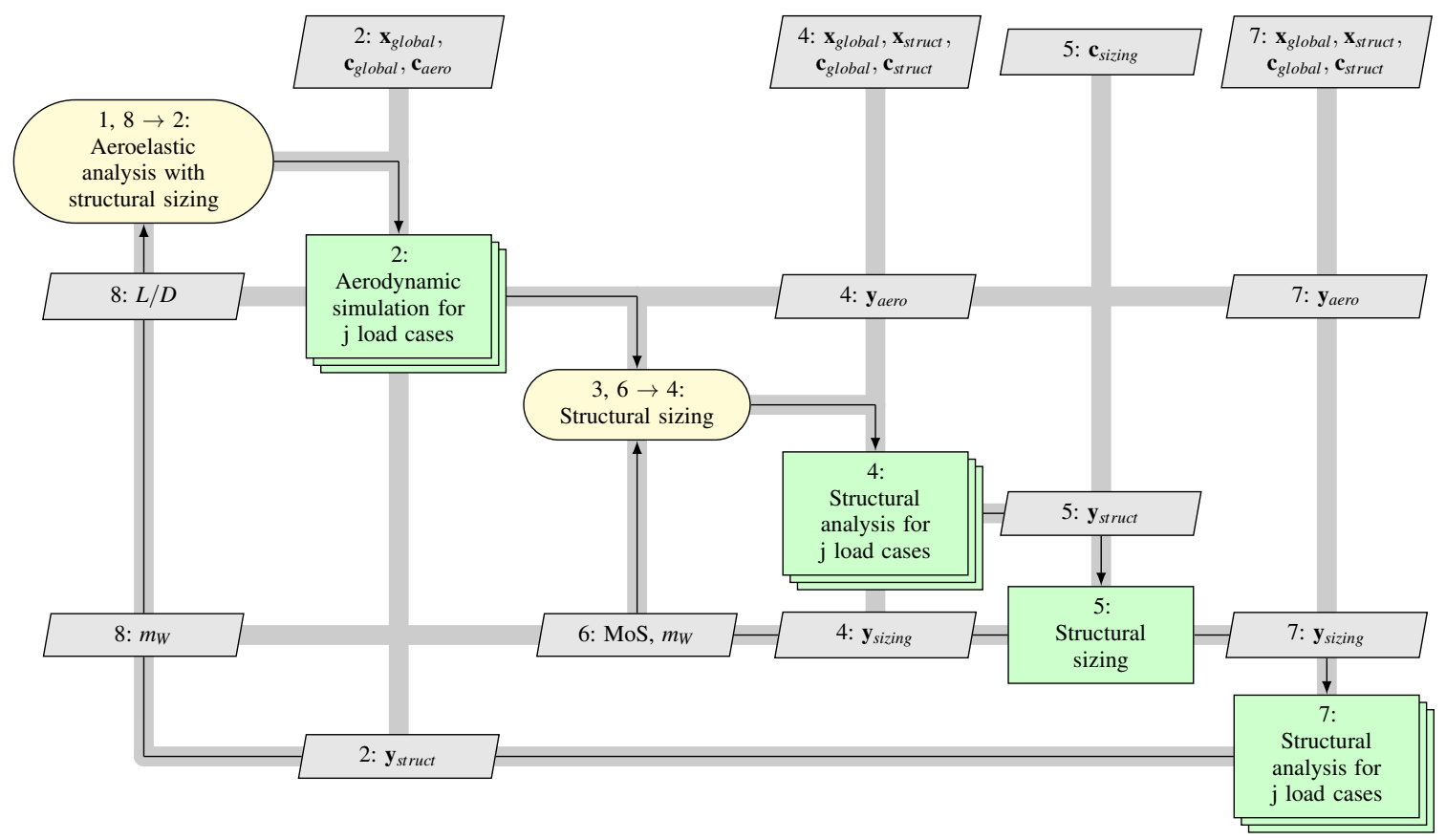

Fig. 2 Flow chart of the parallel aeroelastic analysis including structural sizing.

The internal loads and the resulting wing mass consider secondary masses based on given specific masses for the leading and trailing edge high-lift devices. Furthermore, the interactions between the aerodynamic forces and the structural deformations of the elastic wing are taken into account in the aeroelastic analysis by loosely fluid-structure coupling as described in [28] and [29]. Thereby, the fluid-structure coupling loop stops when the values for the lift-to-drag ratio, wing mass and fuel consumption are converged. The fluidstructure coupling loop is shown in Fig. 1 by a yellow rounded rectangle.

Fig. 2 gives more insight into the parallel aeroelastic analysis including structural sizing. Within the parallel aeroelastic analysis the wing box structure is sized and the bending and torsional stiffness of the wing converge in the fluidstructure coupling loop. Thereby, the structural sizing forms an inner loop to fulfill the structural constraints in terms of failure criteria and converge the margins of safety (MoS) and the wing mass $m_{W}$ for a fixed aerodynamic load.

The main results of this parallel analysis are the wing mass $m_{W}$ and the deformed wing shape for the design point under cruise flight conditions, which is normally called " $1 \mathrm{~g}$ flight shape". Based on this 1g-flight shape the aerodynamic performance in terms of lift-to-drag ratio $L / D$ is determined.

The last step in the process chain is the evaluation of the objective function $f$ for the multidisciplinary assessment of the wing design. The optimization algorithm then calculates a new set of values for the design parameters based on the value of the objective function. After the optimization run has been finished the optimized vector of design paramet- ers $\mathbf{x}^{\text {opt }}$ represents the main result of the process chain for the corresponding optimization problem.

\subsection{Flight mission and objective function}

For the evaluation of the objective function a simplified model of the flight mission has been used. This model is described in the textbook by Raymer [30] and is often used for preliminary aircraft design.

In this work, the flight mission consist of five segments. Table 1 gives an overview of these flight mission segments and the corresponding aircraft mass fractions. With the exception of the cruise flight segment the values for the aircraft mass fractions have to be prescribed depending on the optimization problem.

\begin{tabular}{lll}
\hline $\begin{array}{l}\text { Segment } \\
\text { number }\end{array}$ & $\begin{array}{l}\text { Mission } \\
\text { segment }\end{array}$ & $\begin{array}{l}\text { Aircraft mass } \\
\text { fraction }\end{array}$ \\
\hline 1 & Warm-up and take-off & $m_{1} / m_{0}$ \\
2 & Climb and accelerate & $m_{2} / m_{1}$ \\
3 & Cruise & $m_{3} / m_{2}$ \\
4 & Descent for landing & $m_{4} / m_{3}$ \\
5 & Landing and taxi & $m_{5} / m_{4}$ \\
\hline
\end{tabular}

Table 1 Flight mission segments and mass fractions.

For the cruise flight segment a constant flight speed $V$ and a given constant lift coefficient $C_{L}$ have been assumed. This is equivalent to the assumption of a continuous cruise 
climb. The flight speed $V$ is determined by the selected design cruise Mach number $M a$ and the flight altitude $H$ at the beginning of cruise flight. In combination with the assumption of constant thrust specific fuel consumption TSFC this leads to the well known Breguet range equation:

$R=\frac{1}{g} \frac{V}{T S F C} \frac{L}{D} \ln \frac{m_{2}}{m_{3}}$

The lift-to-drag ratio $L / D$ of the aircraft for the given lift coefficient $C_{L}$ and the wing mass $m_{W}$ are results of the parallel aeroelastic analysis. Furthermore, the selected flight mission corresponds to the design mission. The outcome of this is that the aircraft mass $m_{0}$ at the start of the mission is equivalent to the maximum take-off mass $m_{M T O}$. For an aircraft the maximum take-off mass $m_{M T O}$ is the sum of the residual mass $m_{\text {Res }}$ (structural mass without the wing), the wing mass $m_{W}$, the payload $m_{P}$, the fuel mass $m_{F}$ and the reserve fuel mass $m_{F, \text { res }}$ :

$m_{M T O}=m_{R e s}+m_{W}+m_{P}+m_{F}+m_{F, r e s}$

To allow the usage of accurate simulation programs with high computing effort in the application of the process chain, the maximum take-off mass $m_{M T O}$ iteration loop is neglected and the maximum take-off mass $m_{M T O}$ is held constant. This limits the optimization problem definition either to the specification of range or the specification of payload. If the optimization problem is well defined, the optimization results either will include the optimal payload for given range or the longest range for given payload. Furthermore, the residual mass ratio $m_{\text {Res }} / m_{M T O}$ is also assumed to be constant, because the optimization is limited to the wing. In accordance with the simple model for the flight mission the reserve fuel mass fraction $m_{F, \text { res }} / m_{F}$ is assumed to be constant as well. The fuel mass $m_{F}$ corresponds to the fuel mass which is required for the design mission and has been calculated with the following equation:

$m_{F}=m_{0}-m_{5}=m_{M T O}-m_{5}$

The objective function $f$ has to be selected based on the lift-to-drag ratio and the wing mass. Options for this selection are the minimization of fuel burn for a given range or the maximization of range for a given payload. Thereby, the objective function has to be derived for fixed maximum takeoff mass.

For the transfer of the simulation results to the aircraft level the three following assumptions have been made.

Firstly, it has been assumed that the tailplane lift coefficient $C_{L, T}$ is constant. This means that the adaptation of tailplane lift for aircraft trimming has been neglected. The sum of wing and fuselage lift coefficients $C_{L, W}+C_{L, F}$ results from the flow simulation and matches the prescribed target lift coefficient for the cruise flight.

Secondly, a constant sum of tailplane and engine cowling drag coefficients (here denoted by $C_{D, \text { res }}$ ) has been assumed. The sum of wing and fuselage drag coefficients $C_{D, W}+C_{D, F}$ is a result of the flow simulation and includes pressure and viscous parts. With these assumptions the aerodynamic performance in terms of lift-to-drag $L / D=$ $C_{L} / C_{D}$ ratio is calculated with the following equation:

$$
\frac{L}{D}=\frac{C_{L}}{C_{D}}=\frac{\overbrace{C_{L, W}+C_{L, F}}^{\text {flow simulation }}+\overbrace{C_{L, T}}^{=\text {const. }}}{\underbrace{C_{D, W}+C_{D, F}}_{\text {flow simulation }}+\underbrace{C_{D, T}+C_{D, E}}_{C_{D, \text { res }}=\text { const. }}}
$$

Thirdly, the wing mass $m_{W}$ is the sum of the wing box mass $m_{W, b o x}$ and the secondary wing masses $m_{W, s e c}$. The secondary wing mass consists of the wing leading and trailing edge masses, which have been prescribed in terms of mass per projected area. Additionally, the wing box mass is computed based on the sized finite element (FE) model and is multiplied by a correction factor of 1.25 to get a more realistic wing mass. This correction factor accounts for additional structural mass, which is not modeled in the idealized wing box model. The usage of high fidelity simulation models does not overcome the existing discrepancy between simulation models and reality, but allows the physical based and more accurate prediction of structural mass changes due to design changes.

\subsection{Parametric model}

For the parameterization of the aircraft the Common Parametric Aircraft Configuration Schema (CPACS) [31] has been selected. This aircraft parameterization scheme uses the widely spread Extensible Markup Language (XML). Hence, the CPACS dataset represents a hierarchical organized ASCII text file format.

The usage of CPACS offers a generic and fully parametric description of the aircraft. The geometrical description in CPACS is section based and developed for low-fidelity tools in conceptual design. For the usage in the context of high fidelity simulation methods this geometrical description is not accurate enough. Therefore, some extensions have been introduced to the geometry description in CPACS through the definition of guide curves. These guide curves describe the surface geometry between the fuselage and wing sections respectively and will be used for the surface lofting. The resulting quality of the outer surface geometry is therefore appropriate for aerodynamic simulations with CFD methods.

In CPACS the inner geometry is defined based on the outer geometry description. This includes for example the 
parametric arrangement of spars and ribs. Also the used materials with their properties have to be defined in the CPACS dataset. The structural model generation process is linked to the CPACS dataset and introduced in section 2.5.

Additionally, the definitions of operational cases and load cases for structural sizing are part of the CPACS dataset.

For the aerodynamic simulations a CAD model has been built automatically within the commercial software system CATIA $^{\circledR}$ V5 based on the geometry description in CPACS. This parametric CAD model represents a direct copy of the geometrical description in CPACS with the same parametric description. The main task of the CAD model is the computation of the resulting surfaces and intersections for a given set of geometrical parameters in CPACS. In addition the CAD model includes the auxiliary geometry for the aerodynamic grid generation process.

This approach allows the fast and automated construction of a parametric CAD model, which provides the necessary interfaces to the CPACS dataset and the aerodynamic grid generation. Furthermore, the parametric CAD model allows fast and robust geometrical changes based on the CPACS parameters for a fixed aircraft topology.

\subsection{Aerodynamic grid generation process}

The automated CAD model generation in CATIA ${ }^{\circledR}$ includes the construction of the auxiliary geometry for the structured grid generation as mentioned before. Additionally, this CAD model generation program writes the control script for the structured aerodynamic grid generation using the commercial program Pointwise ${ }^{\circledR}$.

In combination with the generated control script the extended CAD model forms the input for the automatic aerodynamic grid generation with Pointwise ${ }^{\circledR}$. The control script includes all commands for the automatic generation of the structured aerodynamic grid.

In Fig. 3 the surface grid of the reference aircraft configuration is shown as an example. It also includes some details of the leading and trailing edge.

To minimize the number of grid points an O-O-topology is used. Each airfoil section is discretized with 170 points. The resulting aerodynamic grid consists of $2.5 \cdot 10^{6}$ points. This grid resolution represents an appropriate trade-off between accuracy and computing effort for wing optimizations.

The introduced approach allows the fast and automatic grid generation for geometrical changes controlled by design parameters within the optimization loop. Furthermore, the number of grid points is kept constant and the optimization process can be accelerated by using a fully converged flow solution as the starting point for solving the flow

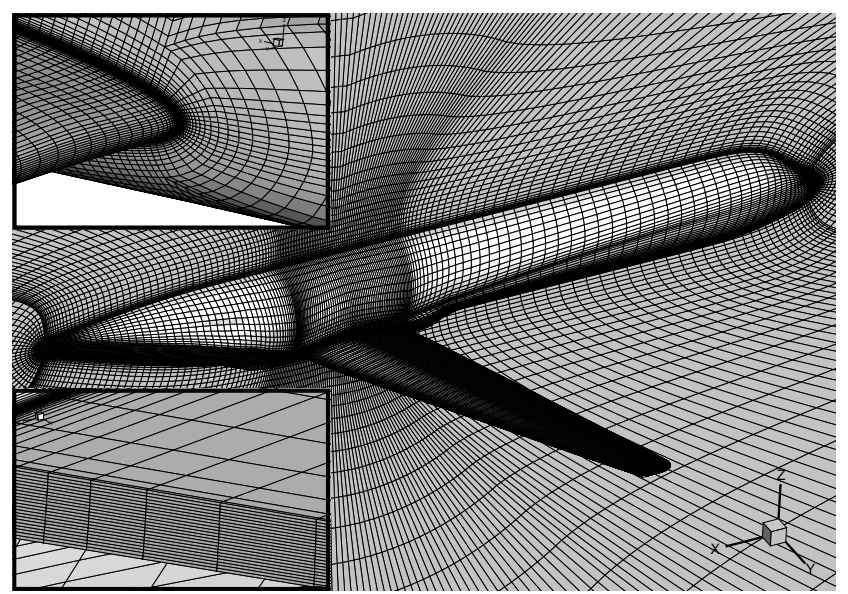

Fig. 3 Aerodynamic surface grid of the reference aircraft configuration with some details of the leading and trailing edge.

field around the modified aircraft geometry. With the usage of structured aerodynamic grids the grid dependent numerical noise is very low for geometrical changes, which is essential for accurate optimization results.

The actual implementation of the automated structured grid generation process is limited to the wing-fuselage configuration. But the introduced procedure is of general applicability to aerodynamic grid generation in the context of MDO.

\subsection{Flow solver}

The transonic flow around the wing-fuselage configuration is simulated with the DLR TAU-code [32], [33], [34], which has been developed at the DLR Institute of Aerodynamics and Flow Technology. The TAU-code solves the compressible, three-dimensional Reynolds-averaged Navier-Stokes equations. It is a well established tool for aerodynamic applications at DLR, universities and aerospace industry [35], [36], [4]. The TAU-code uses a vertex centered dual mesh formulation. For spatial approximation, a finite volume method with second order upwind or central discretization is used.

For the flow simulation within the multidisciplinary process chain the central discretization schema and the negative Spalart-Allmaras turbulence model [37] is currently being used.

\subsection{Structural model generation process}

For the generation of structure models, the software DELiS (Design Environment for thin-walled Lightweight Structures) has been selected. The core of DELiS is a parametric model generator that supports various levels of detail. 
Based on a CPACS dataset, DELiS creates an abstract and object oriented model of the aircraft. This model contains all the structurally relevant CPACS information and enriches it with required data for finite elements. Due to the abstract and FE-centric definition of the lightweight structure, models for various FE solvers can be created, such as MSC Nastran ${ }^{\text {TM }}$ and ANSYS ${ }^{\circledR}$ [38]. In Fig. 4, the conversion of this dataset to an FE model by DELiS is shown exemplarily. From the structural side only the wing is being regarded.

In the scope of the AeroStruct project, two major enhancements to the automated model generation were implemented, namely the configuration-specific evaluation of fuel masses and secondary masses. As runtime plays an important role in predesign where numerous configurations have to be regarded, the aim in terms of efficiency was to consider load relief by fuel and secondary masses while keeping the overall model generation as fast as possible.

For the calculation of the fuel distribution, fuel tanks need to be defined in the dataset. Tank regions are based on references to existing ribs and spars. Together with a maximum fill level, accounting for unusable volumes, components that are not modelled like pumps, fuel expansion reserves etc., the available volume can be calculated per rib bay and tank. In the next step, the fuel is then successively distributed to the tanks for each load case, whereby the outermost tank is filled first. When fill levels have been determined the fuel mass of each rib bay is applied to a point in the middle of the rib bay, which in turn is connected to the corner points by a Nastran RBE3 element. No rotational inertia is being considered due to the liquid phase of the fuel. In the last step, point masses are converted to forces based on the acceleration of the specific load case. This is necessary to handle different fuel distributions in one FE calculation.

Leading and trailing edge high-lift devices are not explicitly modelled. In order to consider their respective masses, a simplified approach has been chosen which is well established in predesign [39]. Semi-empirical values for these regions are taken from the literature in terms of mass per unit area. Based on these values and the projected areas of the individual configuration, the spanwise mass distribution is evaluated. Finally point masses are created per rib bay with the same modelling approach as for the fuel masses (except the conversion to forces as the secondary masses are the same across all load cases). Rotational inertia is neglected as it is hardly assessable without further information about the type of high-lift device.

In Fig. 5, the FE representations of fuel and secondary masses are shown exemplarily. As previously described, fuel masses are converted to forces as they do vary between load cases. It should be mentioned that rib positions are constant along the chord in this case but that is not necessarily the case.

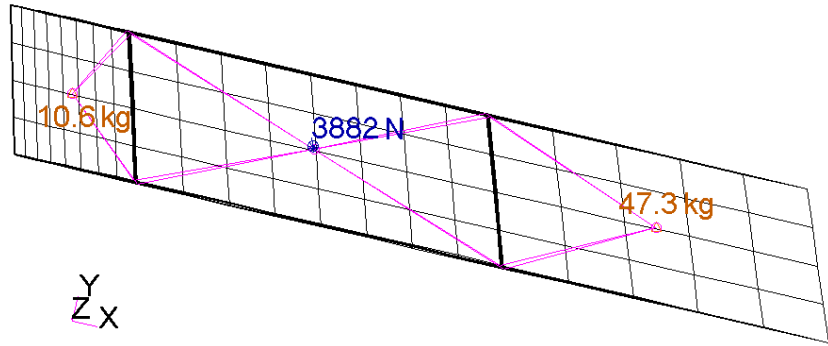

Fig. 5 Rib bay with fuel and secondary masses.

\subsection{Structural analysis and sizing}

The aim of the structural sizing and optimization process is the minimization of the wing box mass $m_{W, b o x}$ with respect to a set of failure criteria. Thereby, all margins of safety $(\mathrm{MoS})$ must be above $\mathrm{MoS}_{r e q}$ :

$\begin{array}{ll}\text { minimize } & m_{W, \text { box }}\left(\mathbf{x}_{\text {struct }}\right) \\ \text { subject to } & \operatorname{MoS}_{i}\left(\mathbf{x}_{\text {struct }}\right) \geq \operatorname{MoS}_{\text {req }, i}\left(\mathbf{x}_{\text {struct }}\right)\end{array}$

Based on the CPACS file an FE model of the wing is automatically generated as described in section 2.5. Rules for the discretization of the wing are implemented in the model generator to define optimization regions for wing cover, spars and each rib. With the external loads, which are calculated within the flow simulation and afterwards mapped onto the FE model, the internal loads are calculated with linear-static FE calculations. Subsequently the FE model with its geometry, material properties and loads is passed to the sizing and optimization module.

In this module the geometry is postprocessed and components and assemblies are created. A component is an optimization region. An assembly as composed of all components of the same part like the wing upper cover or the front spar.

In a second step a design concept is assigned to each component. By considering the design concept only in the sizing and optimization module it is possible to investigate different design concepts with the same FE model because stiffeners are only considered explicitly during component sizing. As a result the creation of the FE model is simplified by smearing the stiffness of a stiffener into the overall panel stiffness, and the stringers do not have to be modelled with discrete elements. Furthermore, an optimization of stringer profile and pitch is possible with the same model as well.

Failure criteria are also applied to the components, which serve as constraints for the optimization. Structure mechanical criteria for strength, damage tolerance, global buckling and local buckling can be used for the sizing of the components. Dähne et al. [24] have shown that global 


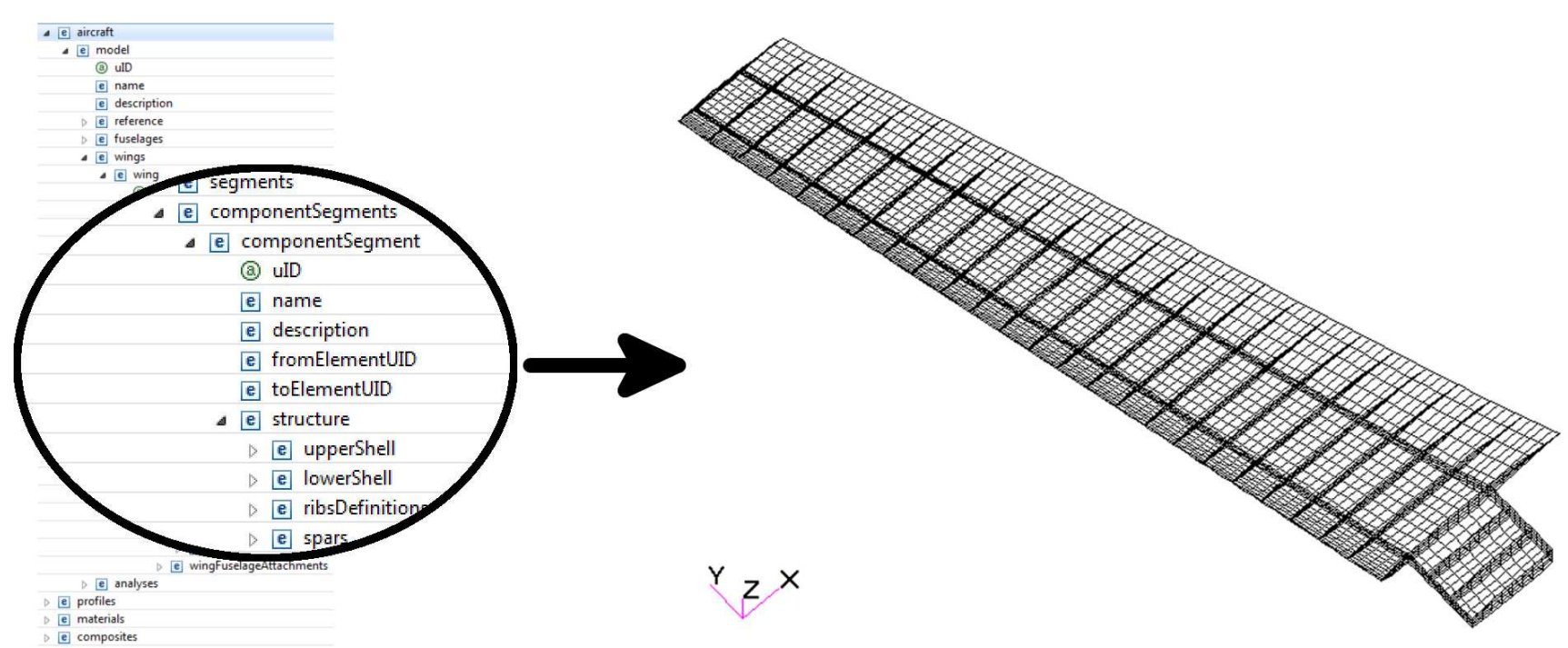

Fig. 4 CPACS with structural part highlighted and FE model created by DELiS.

buckling, local buckling and strength are necessary failure criteria for reasonable results of mass and deformation. The failure criteria used for structural analysis are global buckling, local buckling and maximum strain for skin and stiffener. All criteria have been evaluated at ultimate load. Damage tolerance constraints have been covered by adapted strain allowables. For the strain allowable at ultimate load a conservative value of $3500 \mu \mathrm{m} / \mathrm{m}$ has been chosen as proposed in Military Handbook [40]. Furthermore criteria from manufacturing and operations like minimum and maximum ply share in $0^{\circ} / 90^{\circ} /+45^{\circ} /-45^{\circ}$ direction, minimum and maximum height for stringer webs and a minimum skin thickness for repair have been considered.

The component sizing itself is performed within the commercial software HyperSizer ${ }^{\circledR}$ [41]. The creation of components and assemblies as well as the assignment of the design concept and the failure criteria is done in HyperSizer ${ }^{\circledR}$. An internal object model is created for each component. The object model contains all geometric parameters like stringer spacing, stringer height, skin thickness and web thickness. Fig. 6 exemplarily shows the geometric parameters for a blade-stiffened panel. In addition, the material properties and failure criteria are also part of this object model.

The internal stresses are calculated from internal loads coming from the FE calculation and the stiffness of the panel objects. Due to the permutation based approach of HyperSizer ${ }^{\circledR}$ a great number of design candidates can appear which are reduced by an adaptive process based on the margin of safety. The resulting stiffness properties are evaluated by a subsequent FE calculation. This process is iterated until all failure criteria are fulfilled and the mass change is lower than the convergence threshold.

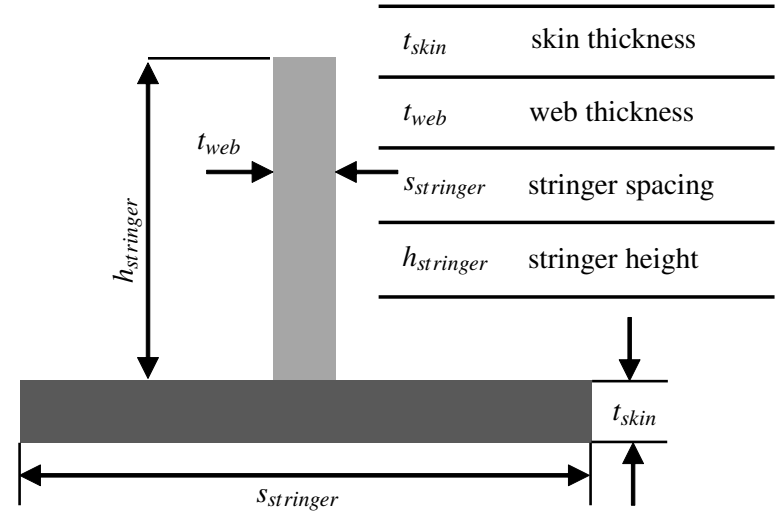

Fig. 6 Blade-stiffened panel parameters.

\subsection{Fluid-structure coupling}

The fluid-structure interaction loop to be carried out in each of the parallel aeroelastic analyses of Fig. 1 involves the following operations:

1. Compute the aerodynamic loads on the given CFD grid for every load case $j$,

2. Interpolate the loads from the CFD surface grid to the structural model,

3. Perform the structural sizing (once the loads of all load cases are available),

4. Compute the structural deformations for the newly sized structure for every load case $j$ and

5. Adjust the CFD volume grid according to the resulting structural deformations.

Then the loop starts over again. In step 2, an efficient classical nearest-neighbor interpolation is applied. It ensures equilibrium of forces on fluid and structural side. The ex- 
isting defect in the equilibrium of moments is negligible. In step 5, a fast and robust grid deformation method is used which is based on the scattered data interpolation technology using radial basis functions. Based on the occurring structural deformations, a volume spline is determined which is then evaluated in parallel at all CFD volume grid points. Consult the publication by Barnewitz [42] for more detailed information on the grid deformation method.

The outlined fluid-structure interaction procedure is scripted in the FlowSimulator environment. The FlowSimulator has been designed particularly for massively-parallel multidisciplinary simulations with high fidelity tools [43]. It is being jointly developed by Airbus, ONERA, DLR and universities. Its core, a $\mathrm{C}++$ layer, provides parallel data containers and associated methods that support an efficient inmemory data exchange between involved process components. A Python scripting layer representing the users' level of access facilitates a fast creation of complex multidisciplinary process chains [44].

For the convergence of the fluid-structure coupling loop several convergence criteria have been used in parallel. A list of all considered physical quantities and their corresponding convergence criterion is shown in Table 2. If all these convergence criteria are fulfilled simultaneously, the aeroelastic equilibrium will be considered as having been achieved and the fluid-structure coupling loop will be terminated.

\begin{tabular}{llc}
\hline Physical quantity & & Convergence criterion \\
\hline Lift-to-drag ratio & $L / D$ & $\frac{\Delta(L / D)}{L / D} \leq 0.001$ \\
Wing mass & $m_{W}$ & $\frac{\Delta m_{W}}{m_{W}} \leq 0.005$ \\
Fuel consumption & $F C=m_{F} /\left(R \cdot m_{P}\right)$ & $\frac{\Delta F C}{F C} \leq 0.002$ \\
\hline
\end{tabular}

Table 2 Convergence criteria of the fluid-structure coupling.

The selected values represent an appropriate trade-off between accuracy and computing time for the wing optimizations. The application of the process chain shows 4-8 fluidstructure coupling iterations $n_{c p l}$ in practice to reach convergence. Fig. 7 gives an example for the fluid-structure coupling convergence. Thereby, the used convergence criteria are shown as error bars.

The increase of wing mass at the beginning of the fluid structure coupling can be explained with the aeroelastic bending-torsion coupling of the forward swept wing. With increasing bending deformation the center of lift moves outboard and the resulting structural load increases. Additionally, Fig. 7 shows a decreasing lift-to-drag ratio under cruise flight conditions. This is a consequence of the elastic wing deformations. The convergence of the fuel consumption is reached after 4 fluid-structure coupling iterations. With the usage of several convergence criteria for the fluid-structure

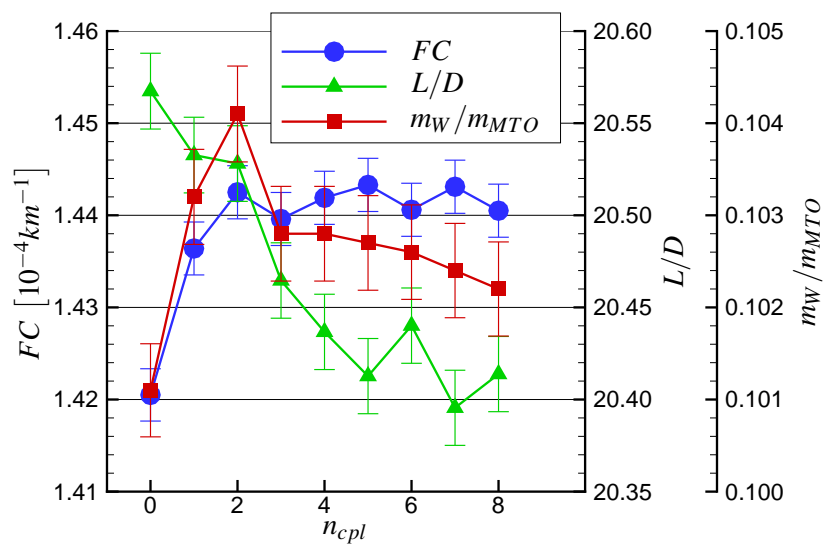

Fig. 7 Fluid-structure coupling convergence with used convergence criteria as error bars.

coupling up to the aeroelastic equilibrium the comparability of results for different geometries can be guaranteed within the multidisciplinary wing optimization.

\subsection{Optimization method}

To control the process chain the program POT (Powerful Optimization Toolkit) [45] has been integrated. This program has been developed by the DLR Institute of Aerodynamics and Flow Technology and provides several optimization methods.

For the multidisciplinary wing optimizations a surrogate based optimization (SBO) method has been selected. This optimization method searches the global optimum and offers a high level of robustness. A similar optimization method named EGO (Efficient Global Optimizer) has been introduced by Jones et al. [46] and is discussed in Forrester et al. [47].

The optimization method starts with a design of experiments (DoE) for a selected number of samples. For the calculated objective function values, a surrogate model based on kriging [48] is built. This surrogate model is able to model nonlinear function behavior and includes a statistical error estimation.

The resulting surrogate model is then used for the optimization with a hybrid optimization strategy. Thereby, the expected improvement (EI) is used as the objective function. The optimization starts with a global optimization method and the localization of the optimum is improved by the application of a local optimization method. For the resulting global optimum of the surrogate model a recalculation is performed. The result of this recalculation is then used to improve the surrogate model. The described procedure is iterated until convergence is reached. 


\section{Multidisciplinary wing optimization}

The introduced process chain as described in section 2 has been used for the multidisciplinary wing optimization of a forward swept wing aircraft configuration. Thereby, the laminar airfoils of the reference aircraft configuration have been used in the optimization. To consider the drag reduction of laminar flow the laminar-turbulent transition has been prescribed at a fixed percentage in chord direction. The goal of this optimization is to show first optimization results and demonstrate the applicability of the developed process chain.

\subsection{Optimization problem description}

\subsubsection{Reference aircraft configuration}

In the DLR project LamAiR [20] a multidisciplinary wing design of a forward swept wing with NLF and a composite structure including aeroelastic tailoring has been performed [22]. This aircraft configuration has been selected for the multidisciplinary wing optimization. Furthermore, the top level aircraft requirements and the design mission are identical to this aircraft configuration. The reference aircraft configuration has a low wing, rear mounted engines and a T-tail as shown in Fig. 8 and represents a short range commercial aircraft in the Airbus A320 and Boeing 737 class.

With the objective of drag reduction by maximizing the extension of laminar flow for a design cruise Mach number of $M a=0.78$, the choice for a forward swept wing configuration is well-founded. For tapered wings, the forward swept wing design allows the favorably low leading edge sweep angle of $\varphi_{L E}=-17^{\circ}$ for a passive control of cross flow instabilities in the leading edge region. Simultaneously, a sufficiently high sweep angle near the mid-chord shock position in the order of $\varphi=-25^{\circ}$ is maintained, to meet the requirement of low wave drag in cruise flight for realistic wing thickness distributions and lift coefficients. Regarding these aspects, the forward swept wing design offers a clear advantage for NLF design under transonic cruise flight conditions in comparison to backward swept configurations.

The disadvantage of the forward swept wing is its inherent tendency for static aeroelastic divergence. Static aeroelastic effects are considered in the process chain by fluidstructure coupled simulations for all computed flight design points and maneuver load cases. The integrated structural sizing process prevents aeroelastic divergence by material thickness and ply share adaptation to the current internal loads. Convergence of the fluid-structure coupling loop is reached for a divergence free wing design.

Some penalty in high-lift efficiency is expected due to the pronounced sweep of the trailing edge. However, the straight trailing edge of the mono-trapezoid wing planform
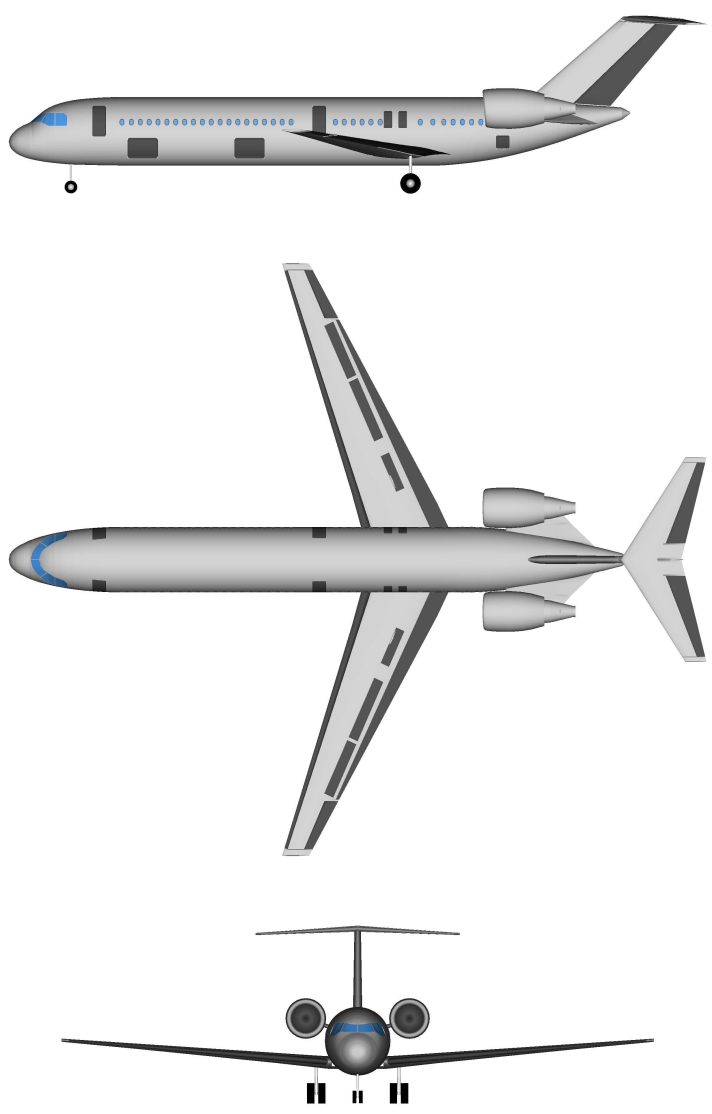

Fig. 8 Reference aircraft configuration.

and the rear mounted engine layout allow an efficient continuous trailing edge flap design. To fulfill the surface requirements for laminar flow the reference aircraft has a smart leading edge high-lift system as proposed by the DLR Institute of Composite Structures and Adaptive Systems [49]. This smart leading edge high-lift system comprises a flexible end-to-end skin without gaps and steps including a kinematical mechanism in style of an active rib for the downward deformation of the leading edge.

\subsubsection{Design parameters and constraints}

The parametric model of the reference aircraft configuration is generated based on the selection of 12 fuselage sections and 9 wing sections. Additionally, 5 guide curves have been used for the geometry description between the fuselage sections and 3 guide curves for the geometry description between the wing sections. Thereby, the guide curves of the wing form the wing leading edge and the upper and lower line of the blunt trailing edge. In Fig. 9 the positions of the selected wing sections are shown for the reference aircraft configuration. 
The selected design parameters for the wing optimization of the reference aircraft configuration are:

- Aspect ratio $A$,

- Leading edge sweep angle $\varphi_{L E}$,

- Taper ratio $\lambda$,

- Twist and thickness distribution $\varepsilon_{i},(t / c)_{i}$,

- Orthotropy angle of the composite material $\varphi_{O D}$.

For the variation of the twist and thickness distribution the values in 4 wing sections have been used respectively. This leads to a total number of 12 design parameters.

The optimizer does not directly control the design parameters. Scaling factors are used for the control of the aspect ratio, taper ratio and thickness distribution, and differences are used for the control of the leading edge sweep angle, twist distribution and the orthotropy angle. Thereby, the scaling factors and the differences are based on the corresponding values of the reference aircraft configuration.

In Fig. 9 the selected definition of design parameters is shown. The twist distribution parameters control the twist angles $\varepsilon_{i}$ in the wing sections 3,4,6 and 9. For the control of the thickness distribution the thickness parameters $(t / c)_{i}$ in the wing sections $1,4,6$ and 8 have been used. In the wing sections between the values for the twist angle and relative thickness are calculated by linear interpolation of the corresponding scaling factors and differences.

For the aeroelastic tailoring of the wing the complete orthotropic material including the stringers of the upper and lower wing box skin is rotated. The orthotropy angle of the composite material $\varphi_{O D}$ is defined relative to the mean line of the wing box as shown in Fig. 9. In the unswept center wing box the orthotropy angle of the composite material has been held constant.

The optimization constraints are listed in Table 3 and are based on the top level aircraft requirements and the results of the conceptual aircraft design published in [22]. This includes the specifications of the maximum take-off mass $m_{M T O}$, wing loading $m_{M T O} / S$ and the cruise Mach number $M a$.

For the structural sizing of the wing box three maneuver load cases with minimum and maximum load factors from the certification specifications CS-25/FAR 25 have been selected. The definitions of the cruise flight design point and the selected load cases are specified in Table 4 and are based on the flight envelope of the reference aircraft configuration. For all of these selected flight design points and maneuver load cases the fluid-structure coupling loop with integrated structural sizing prevents static aeroelastic divergence of the forward swept wing.

The NLF airfoil shapes are transferred from the reference aircraft configuration. In the flow simulation the natural laminar flow is considered by prescribing the laminarturbulent transition of both wing sides at $x_{T} / c=0.3$ for the

\begin{tabular}{lcl}
\hline Aircraft & & \\
\hline Maximum take-off mass & $m_{M T O}$ & $73365 \mathrm{~kg}$ \\
Maximum payload & $m_{P, \max }$ & $19250 \mathrm{~kg}$ \\
Wing loading & $m_{M T O} / S$ & $556 \mathrm{~kg} / \mathrm{m}^{2}$ \\
Residual mass ratio & $m_{R e s} / m_{M T O}$ & 0.4604 \\
$\begin{array}{l}\text { Drag coefficient of tailplane } \\
\text { and engine cowling }\end{array}$ & $C_{D, r e s}$ & 0.0025 \\
$\begin{array}{l}\text { Specific mass of leading } \\
\text { edge high-lift device }\end{array}$ & $m_{l e} / S_{l e}$ & $30 \mathrm{~kg} / \mathrm{m}^{2}$ \\
$\begin{array}{l}\text { Specific mass of trailing } \\
\text { edge high-lift device }\end{array}$ & $m_{t e} / S_{t e}$ & $50 \mathrm{~kg} / \mathrm{m}^{2}$ \\
\hline Design mission & & \\
\hline $\begin{array}{l}\text { Mach number } \\
\text { Range }\end{array}$ & $M a$ & 0.78 \\
Range cruise segment & $R$ & $4815 \mathrm{~km}$ \\
Lift coefficient aircraft & $R_{23}$ & $3726 \mathrm{~km}$ \\
Lift coefficient tailplane & $C_{L}$ & 0.5 \\
Thrust specific fuel & $C_{L, T}$ & -0.0022 \\
consumption & $T S F C$ & $0.0589 \mathrm{~kg} /(\mathrm{Nh})$ \\
Take-off and climb & & \\
mass fraction & $m_{2} / m_{0}$ & 0.9589 \\
$\begin{array}{l}\text { Descent and landing } \\
\text { mass fraction }\end{array}$ & $m_{5} / m_{3}$ & 0.9906 \\
Reserve fuel mass fraction & $m_{F, r e s} / m_{F}$ & 0.4604 \\
\hline
\end{tabular}

Table 3 Constraints of the wing optimization.

\begin{tabular}{lrrccc}
\hline $\begin{array}{l}\text { Load } \\
\text { case }\end{array}$ & Altitude & $\begin{array}{c}\text { Mach } \\
\text { number } \\
M a\end{array}$ & $\begin{array}{c}\text { Lift } \\
\text { coefficient } \\
C_{L, W}+C_{L, F}\end{array}$ & $\begin{array}{c}\text { Aircraft } \\
\text { mass } \\
m\end{array}$ & $\begin{array}{c}\text { Load } \\
\text { factor } \\
n\end{array}$ \\
\hline Cruise & $10668 \mathrm{~m}$ & 0.780 & 0.502 & $68640 \mathrm{~kg}$ & 1.0 \\
LC_2 & $0 \mathrm{~m}$ & 0.597 & 0.539 & $73365 \mathrm{~kg}$ & 2.5 \\
LC_3 & $4725 \mathrm{~m}$ & 0.772 & 0.571 & $73365 \mathrm{~kg}$ & 2.5 \\
LC_4 & $0 \mathrm{~m}$ & 0.597 & -0.216 & $73365 \mathrm{~kg}$ & -1.0 \\
\hline
\end{tabular}

Table 4 Cruise flight design point and load cases for the structural sizing of the wing.

inboard wing and $x_{T} / c=0.4$ for the middle wing and the outboard wing. Furthermore, the leading edge sweep angle is limited to $\left|\varphi_{L E}\right| \leq 17^{\circ}$ due to crossflow instabilities and attachment line transition [17].

The wing box mass $m_{W, b o x}$ resulting from the structural sizing process is multiplied by a factor of 1.25 to account for additional masses which are not modeled in the idealized finite element model [50]. This is required to get a realistic wing mass for the evaluation of the objective function.

\subsubsection{Objective function}

Based on the simplified model for the flight mission as introduced in section 2.1 the fuel consumption $F C$ has been selected as the figure of merit for the multidisciplinary wing optimization. The fuel consumption $F C$ is here defined in terms of fuel burn per range and payload $m_{F} /\left(R m_{P}\right)$ for a given range $R$.

The minimization of the fuel burn is an appropriate objective for the multidisciplinary wing optimization of future 


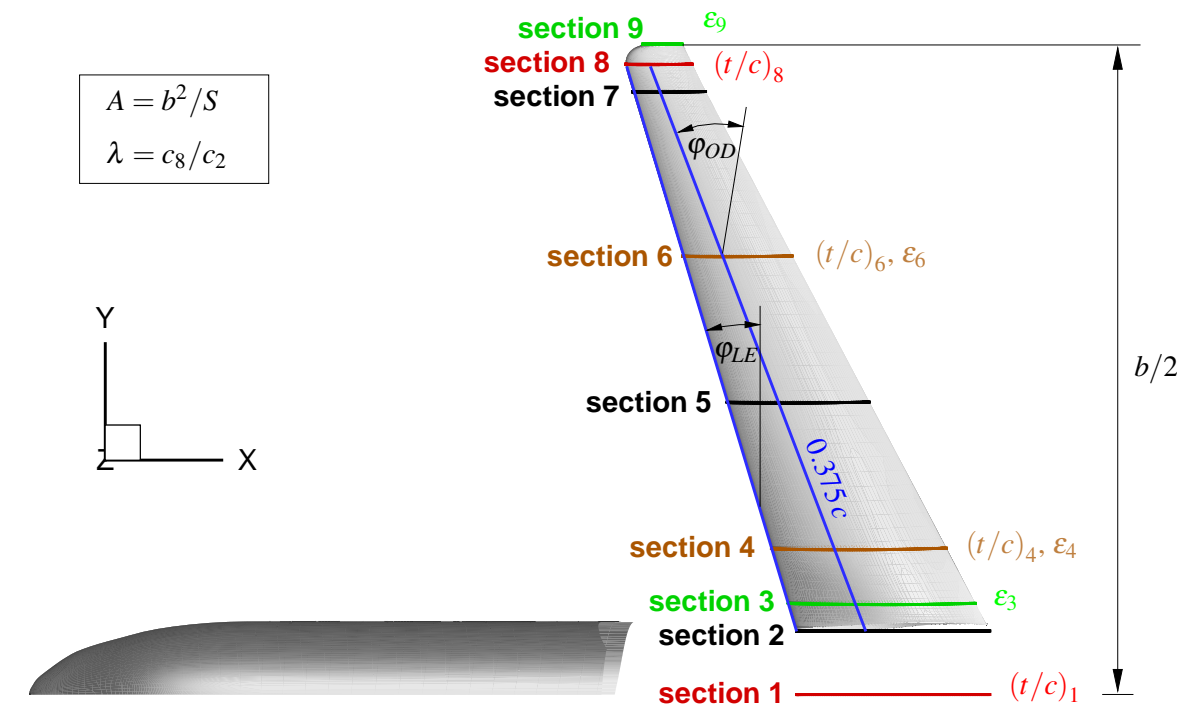

Fig. 9 Definition of design parameters.

commercial aircraft as shown in [51]. This selection results in the optimal trade-off between aerodynamic performance $M L / D$ and wing mass $m_{W}$ in terms of fuel efficiency.

For the calculation of the fuel consumption the required equations are listed in Table 5. Thereby, the fuel mass $m_{F}$ is computed from the given range $R$ and the lift-to-drag ratio $L / D$. The payload $m_{P}$ results from this fuel mass $m_{F}$ and the wing mass $m_{W}$. As mentioned before, the lift-to-drag ratio $L / D$ and the wing mass $m_{W}$ are outputs of the parallel aeroelastic analysis. With all these calculated values the fuel consumption per range and payload $m_{F} /\left(R m_{P}\right)$ follows directly from the last equation shown in Table 5 .

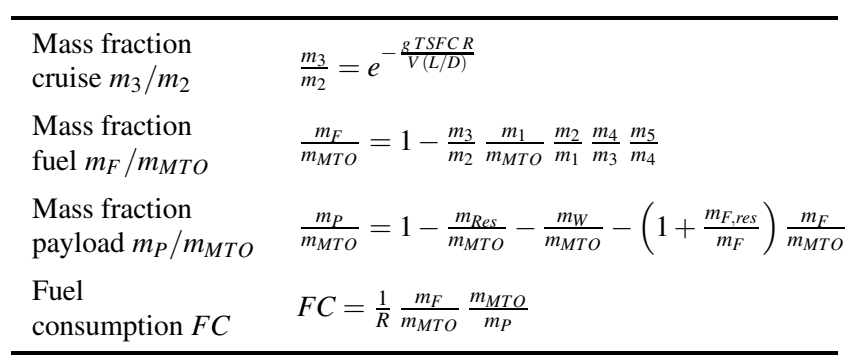

Table 5 Equations for the calculation of fuel consumption.

\subsection{Optimization results}

The wing optimization has been performed successfully for the selected design parameters and constraints.

In Table 6 the wing planform parameters resulting from the optimization are shown for the baseline and the optimized wing. The aspect ratio $A$ of the optimized wing has been increased in comparison to the baseline wing. Furthermore, the leading edge sweep angle $\varphi_{L E}$ remains unchanged and the taper ratio $\lambda$ of the optimized wing is lower than the value of the baseline wing.

\begin{tabular}{|c|c|c|c|}
\hline & & Baseline & Optimized \\
\hline Aspect ratio & $A$ & 9.601 & 11.521 \\
\hline $\begin{array}{l}\text { Leading edge } \\
\text { sweep angle }\end{array}$ & $\varphi_{L E}$ & $-16.8^{\circ}$ & $-16.8^{\circ}$ \\
\hline Taper ratio & $\lambda$ & 0.345 & 0.200 \\
\hline $\begin{array}{l}\text { Orthotropy } \\
\text { angle }\end{array}$ & $\varphi_{O D}$ & $0.0^{\circ}$ & $-5.0^{\circ}$ \\
\hline $\begin{array}{l}\text { Lift-to-drag } \\
\text { ratio }\end{array}$ & $L / D$ & 19.02 & 20.66 \\
\hline Wing mass ratio & $m_{W} / m_{M T O}$ & 0.1001 & 0.1016 \\
\hline Fuel mass ratio & $m_{F} / m_{M T O}$ & 0.2119 & 0.2007 \\
\hline Payload ratio & $m_{P} / m_{M T O}$ & 0.2276 & 0.2373 \\
\hline $\begin{array}{l}\text { Fuel } \\
\text { consumption }\end{array}$ & $F C$ & $1.56 \cdot 10^{-4} \mathrm{~km}^{-1}$ & $1.42 \cdot 10^{-4} \mathrm{~km}^{-1}$ \\
\hline
\end{tabular}

In Fig. 10 the twist distributions of the baseline and optimized wing are shown for the undeformed jig-shape geometry. The twist angles of the optimized wing are similar in the inboard region and increase in the middle region in comparison to the baseline wing. In the outboard region the twist angles of the optimized wing are smaller than the twist angles of the baseline wing.

Fig. 11 shows the relative and absolute thickness distributions of the baseline and the optimized wing. The relative and absolute thickness is nearly identical in the symmetry plane of both wings. With the exception of the sym- 


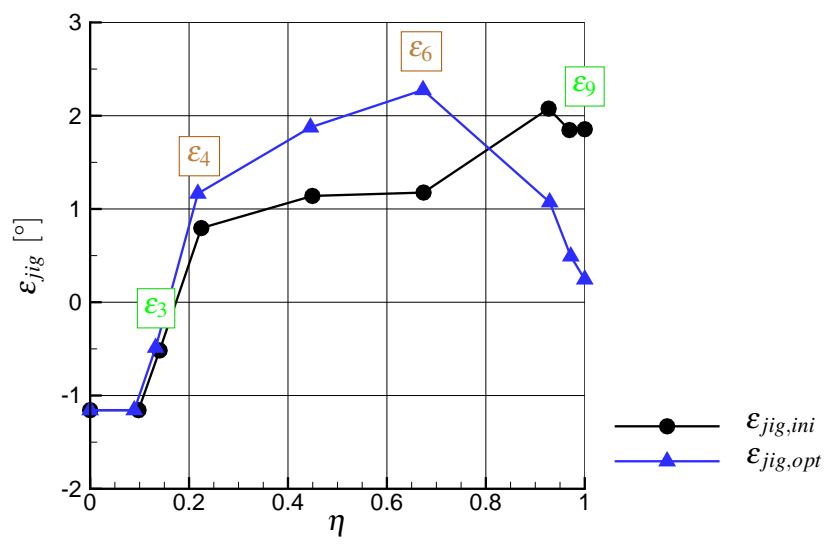

Fig. 10 Twist distributions for baseline and optimized wing.

metry plane and the wing tip the relative and absolute thickness of the optimized wing is decreased in comparison to the baseline wing. In principle the relative airfoil thickness reduction leads to aerodynamic performance improvement and the absolute airfoil thickness reduction results in increased wing mass. The relative low aerodynamic loading in the tip region yields no drag reduction for decreasing the relative airfoil thickness. So the relative thickness in the tip region remains unchanged in comparison to the baseline wing. Additionally, the thickness reduction of the wing leads to a smaller fuel tank volume.

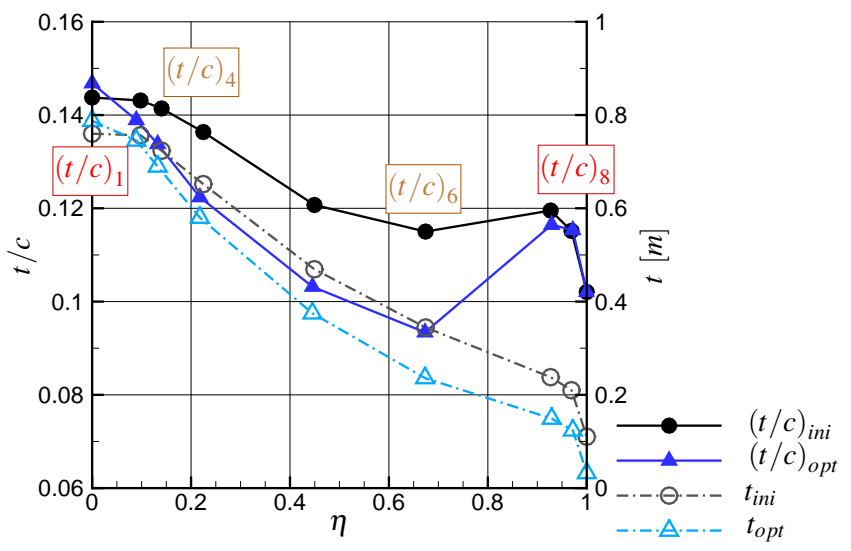

Fig. 11 Relative and absolute thickness distributions for baseline and optimized wing.

The optimization results for the lift-to-drag ratio, the wing mass ratio, the fuel mass ratio, the payload ratio and the fuel consumption are also given in Table 6. These results show an increased aerodynamic performance in terms of lift-to-drag ratio $L / D$ and simultaneously an increased wing mass $m_{W}$ for the optimized wing in comparison to the baseline wing. The increased lift-to-drag-ratio can be explained with the induced drag reduction resulting from the increased span and leads to the reduced fuel mass ratio. It can be observed that the reduced fuel mass $m_{F}$ overcompensates the increased wing mass $m_{W}$. Consequently the payload ratio $m_{P}$ increases. The main result of the wing optimization is the reduction of the fuel consumption $F C$ in the order of $9 \%$.

In Fig. 12, an overview of the wing optimization results for cruise flight condition is given. This includes the comparison of the baseline and the optimized wing in terms of isentropic Mach number distribution for the upper wing, the deformations for the $1 \mathrm{~g}$-cruise flight and the corresponding lift distributions in span direction. For each lift distribution the related elliptical lift distribution is shown with a dot-dashed line as a reference. The elliptical lift distribution is the optimum for planar wings in terms of induced drag. Additionally, the prescribed laminar-turbulent transition line is shown in the isentropic Mach number distribution of Fig. 12. The relative position in chord direction of the laminar-turbulent transition has been held constant within the optimization. The optimized wing shows an inboard load shift and increased bending deformations in comparison to the baseline wing.

Fig. 13 shows the results for load case LC_2 in the same form. An outboard load shift is observed for both wings in comparison to the cruise flight. This outboard load shift of both wings can be explained with the geometrical bendingtorsion coupling of the forward swept wing. Thereby, the optimized wing is more inboard loaded in comparison to the baseline wing. The reason for the reduced bending-torsion coupling of the optimized wing is the aeroelastic tailoring with the orthotropy angle of the composite material. The lift distributions of this $2.5 \mathrm{~g}$-maneuver load case show the importance of considering the static aeroelastic effects in the loads computation for the structural wing sizing. Furthermore, an increased bending deformation of the optimized wing is observed in this maneuver flight.

\subsubsection{Computing time}

The multidisciplinary wing optimization based on high fidelity methods requires a relative high computing effort. For the aerodynamic simulations and the fluid-structure coupling the HPC-cluster $\mathrm{C}^{2} \mathrm{~A}^{2} \mathrm{~S}^{2} \mathrm{E}$ (Center for Computer Applications in AeroSpace Science and Engineering) of the DLR Institute of Aerodynamics and Flow Technology is used. In this work the aerodynamic simulations use 8 nodes of the $\mathrm{C}^{2} \mathrm{~A}^{2} \mathrm{~S}^{2}$ E-cluster, which equates to 192 processor cores. All other simulation programs are executed on local workstations.

An example of the required computing time of the disciplinary simulation programs for a multidisciplinary wing analysis is given in Table 7. In this example 5 fluid-structure 


\begin{tabular}{|c|c|c|c|c|}
\hline Process & Program & Program calls & Computing time & Computing time ratio \\
\hline CAD model update & CATIA $^{\circledR}$ V5 & 1 & $1.5 \mathrm{~min}$ & $1.2 \%$ \\
\hline Aerodynamic grid generation & Pointwise $^{\circledR}$ & 1 & $1.9 \mathrm{~min}$ & $1.5 \%$ \\
\hline Structural model generation & DELiS & 1 & $3.1 \mathrm{~min}$ & $2.5 \%$ \\
\hline Flow simulation and fluid-structure coupling & FlowSimulator (TAU-Code) & 6 & $53.6 \mathrm{~min}$ & $43.6 \%$ \\
\hline Structural analysis and sizing & MSC Nastran $^{\mathrm{TM}}$ and HyperSizer ${ }^{\circledR}$ & 5 & $61.2 \mathrm{~min}$ & $49.8 \%$ \\
\hline \multirow[t]{2}{*}{ Data transfer } & - & - & $1.7 \mathrm{~min}$ & $1.4 \%$ \\
\hline & & & $123.0 \mathrm{~min}$ & $100 \%$ \\
\hline
\end{tabular}

Table 7 Example of the required computing time of the disciplinary simulation programs for a multidisciplinary wing analysis.

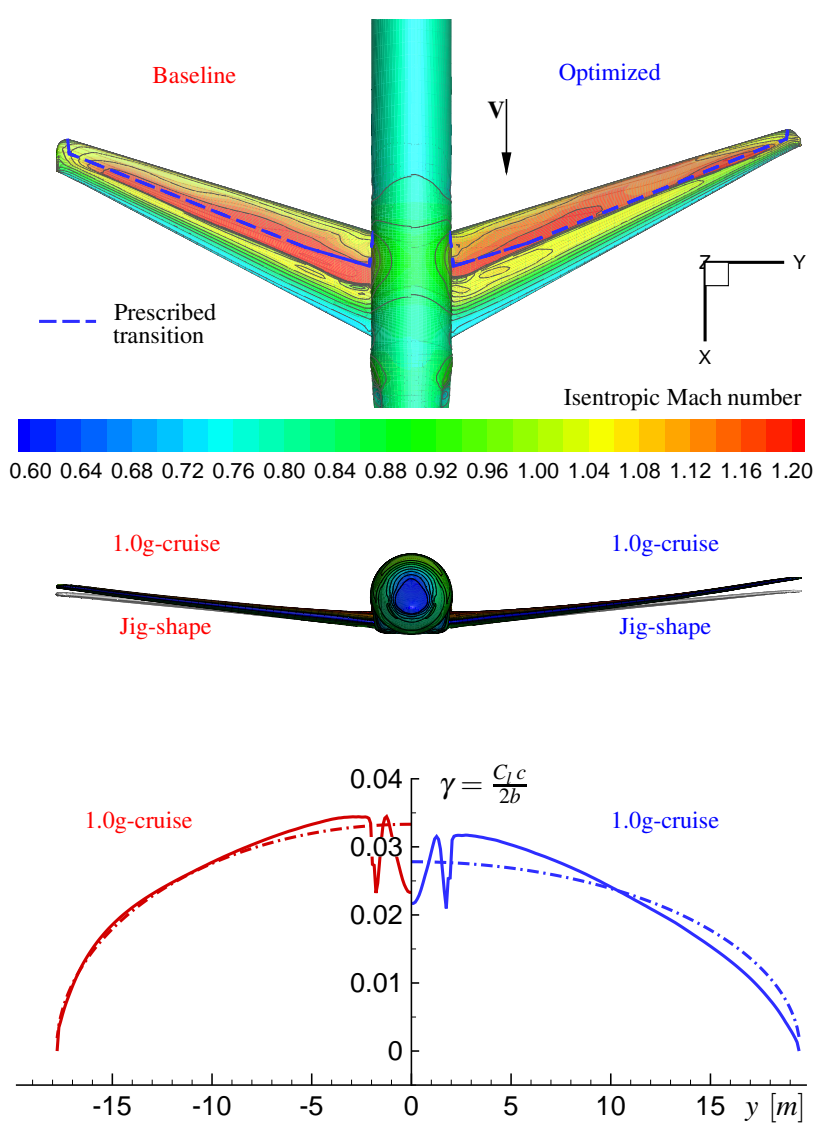

Fig. 12 Overview of wing optimization results for cruise flight.

coupling iterations have been performed to reach the aeroelastic equilibrium of all considered load cases. With approximately $50 \%$, the structural analysis and sizing requires the largest percentage of the computing time. The aerodynamic simulation including the coupling is comparatively efficient due to the high degree of parallelization. It only needs a percentage of computing time in the order of $40 \%$. The waiting time for the cluster queue has not been considered in the indicated computing times.

To summarize, it can be stated that the multidisciplinary wing optimization with 12 design parameters requires an overall computing time in the order of 2 weeks.

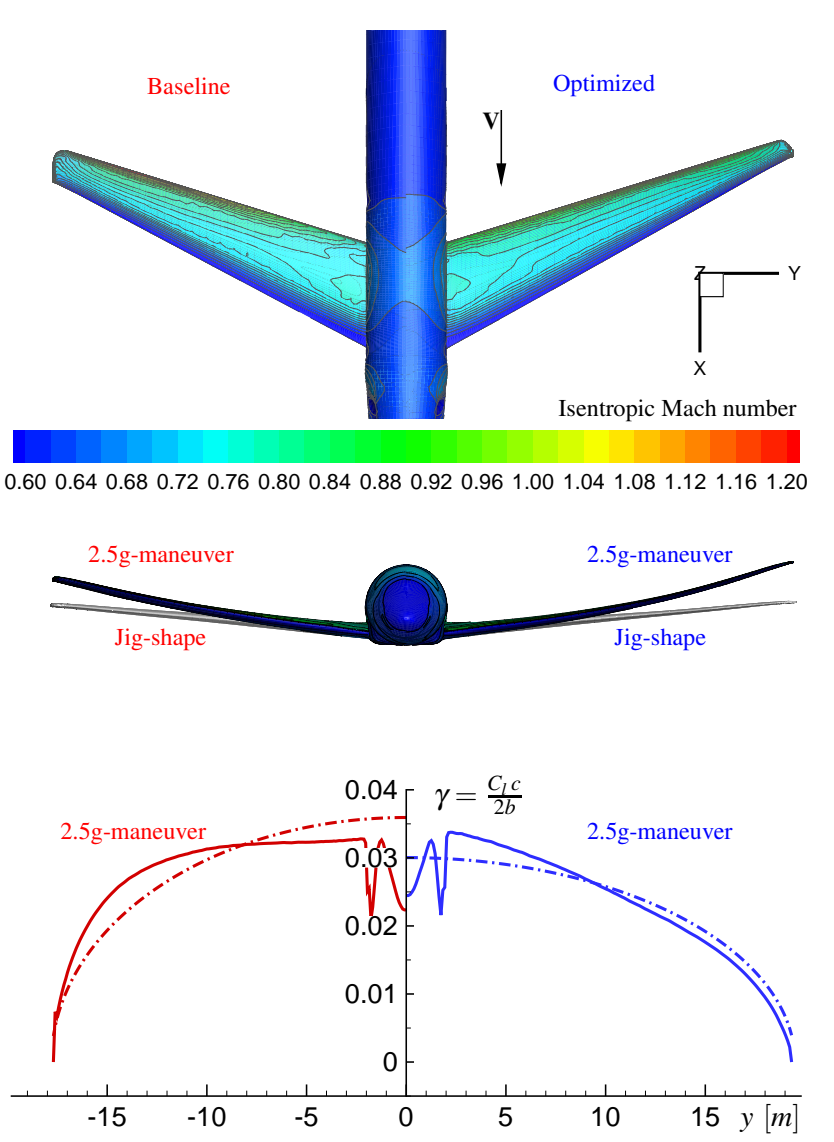

Fig. 13 Overview of wing optimization results for load case LC_2.

\section{Conclusion and outlook}

In the national joint research project AeroStruct a process chain for multidisciplinary wing optimization based on high fidelity simulation methods has been developed. This process chain enables the technologies NLF and aeroelastic tailoring using CFRP in the context of MDO.

The results for the multidisciplinary optimization of an NLF forward swept composite wing show the influence of wing geometry changes and the orthotropy angle of the composite material to the lift-to-drag ratio, the wing mass and the resulting fuel consumption. Thereby, the optimization results in a more flexible wing design with reduced airfoil 
thicknesses and increased aspect ratio. With the corresponding wing span of $b=39 \mathrm{~m}$ the box limit of the FAA Airplane Design Group V and ICAO Aerodrome Reference Code E has been exceeded. In this context the influence of span limits for airport conformity to fuel efficiency has to be reconsidered.

The optimized wing shows a significant increase in aerodynamic performance and a slightly increased wing mass in comparison to the baseline wing. This minor impact of airfoil thickness reduction and increased aspect ratio to the resulting wing mass can be explained by the reduced bendingtorsion coupling due to aeroelastic tailoring. The wing optimization leads to a more flexible wing design with passive maneuver load alleviation. This shows the growing importance of the consideration of aeroelasticity including aeroelastic tailoring in the conceptual aircraft design.

Furthermore, the efficiency and robustness of the parallel aeroelastic analysis including wing box sizing for three load cases has been successfully demonstrated. The application of the optimization process to the forward swept wing shows a successful prevention of its inherent tendency for static aeroelastic divergence through the usage of aeroelastic tailoring.

In the demonstration of the introduced process chain the laminar airfoils from the reference aircraft configuration have been used and the NLF is considered with a prescription of the laminar-turbulent transition. The next step is the integration and validation of a laminar airfoil catalogue and a laminar-turbulent transition prediction method in the process chain. Applications with the complete process chain for the MDO of more conventional commercial aircraft with backward swept composite wings are planned.

Acknowledgements This work was funded by the German Federal Ministry for Economic Affairs and Energy (BMWi) as part of the DLR contribution to the LuFo IV joint research project AeroStruct. The authors wish to thank the Institute of Aerodynamics and Flow Technology and the Institute of Composite Structures and Adaptive Systems for providing the support of many colleagues, the IT infrastructure and the computing resources for the complex computations.

\section{References}

[1] European Commision. European Aeronautics: A Vision for 2020. Luxembourg, Belgium: Office for Official Publications of the European Communities, 2001.

[2] European Commision. 2008 Addendum to the Strategic Research Agenda. http://www.acare4europe.com. 2008.

[3] European Commision. Flightpath 2050 Europe's Vision for Aviation. Luxembourg, Belgium: Office for Official Publications of the European Communities, 2011.
[4] N. Kroll et al. "The MEGAFLOW-Project - Numerical Flow Simulation for Aircraft". In: Progress in Industrial Mathematics at ECMI 2004 (2005), pp. 333.

[5] N. Kroll et al. "Ongoing Activities in Shape Optimization Within The German Project MEGADESIGN". In: ECCOMAS 2004. 2004.

[6] N. Kroll et al. "Flow Simulation and Shape Optimization For Aircraft Design". In: Journal of Computational and Applied Mathematics 203 (Dec. 2005), pp. 397-411.

[7] N. Kroll et al. "Ongoing Activities in Flow Simulation and Shape Optimization within the German Megadesign Project”. In: ICAS 2006, 25th International Congress of the Aeronautical Sciences. 2006.

[8] N. Kroll et al. MEGADESIGN and MegaOpt - German Initiatives for Aerodynamic Simulation and $\mathrm{Op}$ timization in Aircraft Design. Springer-Verlag Berlin Heidelberg, 2009.

[9] N. R. Gauger. "Ongoing activities in shape optimization within the German project MEGADESIGN". In: EUCCO2004, Dresden (de), 29.-31.03.2004. 2004.

[10] P. Piperni et al. "Preliminary Aerostructural Optimization of a Large Business Jet". In: Journal of Aircraft 44.5 (2007), pp. 1422-1438.

[11] K. Chiba et al. "Multidisciplinary Design Optimization and Data Mining for Transonic Regional-Jet Wing". In: Journal of Aircraft 44.4 (2007), pp. 11001112.

[12] A. Jameson et al. "Multi-point Aero-Structural Optimization of Wings Including Planform Variations". In: 45th Aerospace Sciences Meeting and Exhibit, Reno, Nevada, USA. AIAA 2007-764. 2007.

[13] G. K. W. Kenway and J. R. R. A. Martins. "Multipoint High-Fidelity Aerostructural Optimization of a Transport Aircraft Configuration". In: 51 (2014). Journal of Aircraft, pp. 144-160.

[14] G. K. W. Kenway et al. "Scalable Parallel Approach for High-Fidelity Steady-State Aeroelastic Analysis and Adjoint Derivative Computations". In: 52 (2014). AIAA Journal, pp. 935-951.

[15] R. P. Liem et al. "Multi-point, multi-mission, highfidelity aerostructural optimization of a long-range aircraft configuration". In: 14th AIAA/ISSMO Multidisciplinary Analysis and Optimization Conference, Indianapolis, USA. Sept. 2012.

[16] K. Horstmann and T. Streit. "Aerodynamic Wing Design for Transport Aircraft - Today: Hermann Schlichting - 100 Years”. In: ed. by R. Radespiel et al. Vol. 102. Springer-Verlag Berlin Heidelberg, 2009, pp. 130-144. 
[17] G. Schrauf. "Status and perspectives of laminar flow". In: The Aeronautical Journal 109.1102 (Dec. 2005), pp. 639-644.

[18] J. E. Green. "Laminar Flow Control - Back to the Future?" In: 38th Fluid Dynamics Conference and Exhibit, Seattle, Washington, USA. AIAA 2008-3728. 2008.

[19] G. W. Hanks et al. Natural laminar flow analysis and trade studies. Tech. rep. NASA CR-159029. National Aeronautics and Space Administration, 1979.

[20] A. Seitz et al. "The DLR Project LamAiR: Design of a NLF Forward Swept Wing for Short and Medium Range Transport Application". In: 29th AIAA Applied Aerodynamics Conference. AIAA Conference Paper AIAA 2011-3526. June 2011.

[21] G. Redeker and G. Wichmann. "Forward Sweep - A Favourable Concept for a Laminar Flow Wing". In: Journal of Aircraft 28 (1991), pp. 97-103.

[22] M. Kruse et al. "A Conceptual Study of a Transonic NLF Transport Aircraft with Forward Swept Wings". In: 30th AIAA Applied Aerodynamics Conference, New Orleans, Louisiana. AIAA Conference Paper AIAA 2012-3208. June 2012.

[23] M. H. Shirk et al. "Aeroelastic tailoring - Theory, practice, and promise". In: Journal of Aircraft 23.1 (1986), pp. 6-18.

[24] S. Dähne et al. "Steps to Feasibility for Laminar Wing Design in a Multidisciplinary Environment". In: ICAS 2014. Sept. 2014.

[25] T. F. Wunderlich. "Multidisciplinary wing optimization of commercial aircraft with consideration of static aeroelasticity". In: CEAS Aeronautical Journal 6.3 (2015), pp. 407-427.

[26] J. R. R. A. Martins and A. B. Lambe. "Multidisciplinary Design Optimization: A Survey of Architectures". In: AIAA Journal 51 (2013), pp. 2049-2075.

[27] A. B. Lambe and J. R. R. A. Martins. "Extensions to the Design Structure Matrix for the Description of Multidisciplinary Design Analysis and Optimization Processes". In: Structural and Multidisciplinary Optimization 46 (2012), pp. 273-284.

[28] R. Kamakoti and W. Shyy. "Fluid-structure interaction for aeroelastic applications". In: Progress in Aerospace Sciences 40.8 (2005), pp. 535-558.

[29] X. B. Lam et al. "Coupled Aerostructural Design Optimization Using the Kriging Model and Integrated Multiobjective Optimization Algorithm”. In: Journal of Optimization Theory and Applications 142.3 (2009), pp. 533-556.

[30] D. P. Raymer. Aircraft Design: A Conceptual Approach. Third Edition. American Institute of Aeronautics and Astronautics, 1999.
[31] C. M. Liersch and M. Hepperle. "A Unified Approach for Multidisciplinary Preliminary Aircraft Design”. In: CEAS European Air and Space Conference, Manchester, United Kingdom. 2009.

[32] M. Galle. Ein Verfahren zur numerischen Simulation kompressibler, reibungsbehafteter Strömungen auf hybriden Netzen. Tech. rep. DLR-Forschungsbericht 9904. Braunschweig: DLR Institut für Aerodynamik und Strömungstechnik, 1999.

[33] T. Gerhold. "Overview of the Hybrid RANS TAUCode, In: Kroll N., Fassbender J. (Eds) MEGAFLOW - Numerical Flow Simulation Tool for Transport Aircraft Design”. In: Notes on Multidisciplinary Design 89 (2005).

[34] D. Schwamborn et al. "The DLR TAU-Code: Recent Applications in Research and Industry". In: European Conference on Computational Fluid Dynamics, ECCOMAS CFD 2006 Conference, Delft, The Netherlands. 2006.

[35] N. Kroll and J. K. Fassbender. "MEGAFLOW - Numerical Flow Simulation for Aircraft Design, Braunschweig". In: Notes on Numerical Fluid Mechanics and Multidisciplinary Design (NNFM) 89 (2002).

[36] N. Kroll et al. "MEGAFLOW - A Numerical Flow Simulation Tool For Transport Aircraft Design, Toronto, Canada". In: ICAS Congress 2002. 2002, pp. 1.105.1-1.105.20.

[37] S. R. Allmaras et al. "Modifications and Clarifications for the Implementation of the Spalart-Allmaras Turbulence Model". In: Seventh International Conference on Computational Fluid Dynamics (ICCFD7). 2012, pp. 1-11.

[38] S. Freund et al. "Parametric Model Generation and Sizing of Lightweight Structures for a Multidisciplinary Design Process". In: NAFEMS Konferenz: "Berechnung und Simulation - Anwendungen, Entwicklungen, Trends. May 2014.

[39] E. Torenbeek. Synthesis of subsonic airplane design. Delft: Delft University Press, 1976.

[40] M.-H.-1.-3. Military. Composite Materials Handbook, Polymer Matrix Composites: Materials Usage, Design, and Analysis. Vol. 3 of 5. US Department of Defense, June 2002.

[41] HyperSizer Documentation. Collier Research Corporation. Newport News, 2015.

[42] H. Barnewitz and B. Stickan. "Improved Mesh Deformation". In: Notes on Numerical Fluid Mechanics and Multidisciplinary Design. Ed. by B. Eisfeld et al. Vol. 122. 2013, pp. 219-243.

[43] M. Meinel and G. O. Einarsson. "The FlowSimulator framework for massively parallel CFD applications". In: PARA 2010 conference, 6-9 June, Reykjavik, Iceland. 2010. 
[44] L. Reimer et al. "Multidisciplinary Analysis Workflow with the FlowSimulator". In: Proceedings of the Onera Scientific Day 2012-CFD Workflow: Mesh, Solving, Visualizing, ... Ed. by C. Benoit et al. Vol. 19. Amphithéâtre Becquerel, École Polytechnique, Palaiseau, 2012, pp. 23-30.

[45] G. Wilke. "Multi-Objective Optimizations in Rotor Aerodynamics using Variable Fidelity Simulations". In: 39th European Rotorcraft Forum. Sept. 2013, pp. 1-13.

[46] D. R. Jones et al. "Efficient Global Optimization of Expensive Black-Box Functions". In: Journal of Global Optimization 13 (1998), pp. 455-492.

[47] A. Forrester et al. Engineering Design via Surrogate Modelling: A Practical Guide. Wiley, 2008.

[48] D. G. Krige. "A Statistical Approach to Some Basic Mine Valuation Problems on the Witwatersrand". In: Journal of the Chemical, Metallurgical and Mining Society of South Africa 52.6 (Dec. 1951), pp. 119139.

[49] M. Kintscher et al. "Design of a smart leading edge device for low speed wind tunnel tests in the European project SADE”. In: International Journal of Structural Integrity 2.4 (2011), pp. 383-405.

[50] G. K. W. Kenway et al. "Aerostructural optimization of the Common Research Model configuration". In: 15th AIAA/ISSMO Multidisciplinary Analysis and Optimization Conference, Georgia, USA. June 2014.

[51] T. F. Wunderlich. "Multidisziplinärer Entwurf und Optimierung von Flügeln für Verkehrsflugzeuge". In: Deutscher Luft- und Raumfahrtkongress, Aachen. DGLR-Tagungsband - Ausgewählte Manuskripte DLRK2009-1181. Sept. 2009. 